\title{
On the Use of Subjective Well-Being Data for Environmental Valuation
}

Susana Ferreira

Mirko Moro

Stirling Economics Discussion Paper 2009-24

December 2009

Online at http://www.economics.stir.ac.uk 


\title{
On the Use of Subjective Well-Being Data for Environmental Valuation*
}

\author{
Susana Ferreira \\ Department of Agricultural and Applied Economics, 313 Conner Hall, University of Georgia \\ Athens, GA 30602. Tel: +1 7065420086 Email: sferreir@uga.edu

\section{Mirko Moro} \\ Division of Economics, University of Stirling, Stirling, FK9 4LA, UK. Tel: +44(0)1786466409 \\ E-mail: mirko.moro@stir.ac.uk \& Economic and Social Research Institute, Dublin, Ireland
}

\begin{abstract}
This paper explores the potential of using subjective well-being (SWB) data to value environmental attributes. A theoretical framework compares this method, also known as the lifesatisfaction approach, with the standard hedonic pricing approach, identifying their similarities and differences. As a corollary, we show how SWB data can be used to test for the equilibrium condition implicit in the hedonic approach (i.e., equality of utility across locations). Results for Ireland show that the equilibrium condition required by the hedonic pricing approach in Irish markets does not hold. They also show that air quality, in the baseline specification, and warmer climate, across all the specifications, have a significant positive impact on SWB. Their associated monetary estimates, however, seem too large.
\end{abstract}

Keywords: environmental valuation, happiness, hedonic pricing, subjective well-being, life satisfaction, climate, air pollution

JEL codes: D1, I31, Q51, Q53, Q54

\footnotetext{
* We thank Finbarr Brereton for access to the GIS dataset and Peter Clinch for access to the survey data. We are grateful to Richard Carson and two anonymous reviewers for helpful comments. Financial support of the Irish Environmental Protection Agency STRIVE programme (Moro) is gratefully acknowledged
} 


\section{Introduction}

As changes in environmental quality have become of greater public concern and an important challenge for public policy, increasing attention has been paid by economists to finding means of eliciting the value of such changes. Since most environmental amenities are not traded in markets and so do not have an obvious price, several methodologies have been developed to estimate their value and the benefits and costs of changes in their quality. The literature on environmental valuation is now very extensive, with its methods typically classified as revealedpreference or stated-preference approaches.

Revealed-preference approaches are indirect valuation methods which are based on the actual behaviour of individuals. These methods utilise complementarity and substitutive relationships between non-marketed and various marketed goods to infer the value attributed to public goods from market transactions in private goods. Examples include the travel cost method and the hedonic pricing (HP) method. On the contrary, stated-preference approaches, such as contingent valuation and choice modelling, are direct methods of eliciting individual's preferences. They rely on asking people hypothetical questions to compute their willingness to pay (WTP) for improvements in environmental quality or their willingness to accept payment in exchange for bearing a particular loss (for reviews on this see Hanley et al., 2001; Bateman et al., 2002).

Recently, a novel method based on subjective well-being (SWB) surveys has been introduced as an alternative tool to valuing amenities. SWB scores have been used in a growing economics literature studying the determinants of individual quality of life (see e.g., Easterlin, 1973, 1974, for early contributions, and Frey and Stutzer, 2002; Di Tella and MacCulloch, 2006; and Clark et al., 2008 for recent surveys). 
However, the potential of life-satisfaction (LS) data goes beyond this. ${ }^{1}$ In particular, they can be used to infer the monetary value of non-marketed goods. One can use self-reported wellbeing as a proxy for the individual's utility and compute directly the marginal rate of substitution between income and non-marketed goods, their elasticity (with respect to income) and other welfare measures (e.g. equivalent and compensating surpluses). For example, Welsch (2002), using cross-sectional data for 54 countries, identifies a negative effect of urban air pollution (in terms of nitrogen dioxide concentration) on average LS that translates into a marginal price of emissions of $\$ 0.07$ per ton. In a more recent study, Welsch (2006) finds a considerable monetary value associated with improvements in air quality in Europe in 1990-1997 (\$750 per capita per year for nitrogen dioxide and $\$ 1400$ per capita per year for lead, on average). ${ }^{2}$ Frey et al. (2004) find that the WTP for a reduction of terrorism in France and the UK to rates that prevail in the more peaceful parts of each country is about $14 \%$ of annual household income in Paris, $32 \%$ in London, and $41 \%$ in Belfast. Luechinger (2009) estimates that the WTP for a marginal improvement in sulphur dioxide concentrations in Germany ranges between $€ 183$ and $€ 313$ per person per year.

The LS approach shares some analogies with both revealed-preference and stated-preference methods. Like stated-preference methods, the LS approach uses a survey methodology in which respondents are asked to evaluate their overall satisfaction with life, happiness, or positive and negative affects. However, people are unaware that their responses will be utilised to derive

\footnotetext{
${ }^{1}$ In this paper we use a LS question to assess SWB and use the terms LS and SWB interchangeably throughout.

${ }^{2}$ During the period 1990-1997, $\mathrm{NO}_{2}$ concentrations fell between 8 percent in the UK and 29 percent in Spain while they increased by 58 percent in Portugal. The drop in lead concentrations ranged from 40 percent in Belgium to 90 percent in Denmark. Luxembourg was the only country in which lead concentrations did not change.
} 
their preferences for public goods. Happiness functions are built where self-reported satisfaction with life is related to individual, social and economic factors and, more recently, to spatial attributes. Like revealed-preference methods, the LS approach elicits the preferences of individuals indirectly. However, a proxy for their utility is directly observable and reliance on private market transactions is not necessary to estimate the implicit prices of amenities.

Some recent studies have recognized the close ties between the HP and LS approaches. Moro et al. (2008) propose quality-of-life indices constructed from SWB data as an alternative to the conventional indices using weights derived from hedonic regressions. Van Praag and Baarsma (2005) and Luechinger (2009) propose adding the monetary estimates computed using the LS approach to those obtained from hedonic regressions to obtain the correct value for environmental amenities. A critical assumption in the HP approach is that wages and housing prices fully adjust to equalize individuals' utility across locations. If this equilibrium condition does not hold due to, for example, market imperfections, moving costs or imperfect information, wages and house prices do not fully capitalize differences in amenities. In this case, the implicit prices calculated using HP are biased and need to be "complemented" with an estimate of the "residual" externality that can be computed using the LS approach.

In this paper, we build on these studies and present a simple theoretical model comparing the HP and LS approaches. Our model generalizes previous results and clarifies how the relationship between the two methods depends on whether the hedonic markets are in equilibrium or disequilibrium and on the econometric specification of the happiness function. Moreover, we show how SWB scores could be used to test for the HP equilibrium condition in a straightforward way, with no need of further information from housing or labour markets. 
Behind the use of SWB data in this and in previous papers, however, there is an implicit assumption that SWB scores are a good proxy for individual's utility. Despite a growing economics literature utilizing SWB scores as a proxy for utility, this issue is still controversial and we discuss it in Section 2.

In the empirical part of the paper, using data on SWB from Ireland in 2001, we first show that the equilibrium condition required by HP does not hold in Irish markets. Second, we estimate a microeconometric happiness function from which we can directly compute the marginal price of local environmental amenities and other measures of welfare change related to infra-marginal amenity changes (equivalent and compensating surpluses). The environmental attributes in our study are linked to each respondent's dwelling area using a Geographic Information System (GIS) data set. The novel use of highly spatially disaggregated data helps overcome the problem of not being able to capture the effects of environmental factors at the geographical level (local or regional) at which the individual experiences them, which has been identified in studies using cross-country observations (see e.g. Welsch 2006, or Smith 2008 for a critique).

The factors identified by our model as affecting individuals' SWB are comparable with previous literature: warmer climatic conditions, across all the specifications, and air quality, in the baseline specification, have a positive and statistically significant effect of well-being as in Frijters and van Praag (1998), Redhanz and Maddison (2005), Welsch (2002 and 2006) and Luechinger (2009). Their associated monetary estimates, however, seem too large. We argue that there might be an upward bias arising from the endogeneity of income, measurement errors and comparison effects. Externalities provided by water pollution, and proximity to landfills have a negative effect, although it is not statistically significant, as in Brereton et al. (2008). 
The paper is structured as follows. Section 2 presents an overview of the HP and LS approaches and a theoretical model illustrating their relationship. Section 3 presents a methodology to compute welfare measures with the LS approach. Section 4 describes the variables and data sources used in our study. Section 5 applies the methodology described in Section 3 to the calculation of the monetary value of location-specific factors in Ireland and presents the estimation results and robustness checks. Section 6 concludes.

\section{Life Satisfaction and Hedonic Pricing approaches: an overview and comparison}

Recent studies identify a common ground between the HP and LS approaches. Both can be applied to analyze the effects of location-specific attributes on individuals' quality of life and preferences about different locations. In particular, both approaches can be used to construct quality-of-life indices to rank locations (Moro et al. 2008), and to value environmental attributes such as noise (van Praag and Baarsma, 2005) or air quality (Luechinger, 2009).

The standard HP method exploits the relationship between the characteristics of a location and house prices and wages (see Rosen, 1974; Roback, 1982; Blomquist et al. 1988 for seminal contributions). When choosing between different locations, individuals make trade-offs that reveal something about the value they place on surrounding local amenities. This choice affects the levels of rents and wages. In equilibrium, wages and rents must adjust to equalize utility across locations; otherwise some individuals would have an incentive to move to locations where they could attain a higher utility. More formally, this can be expressed as

$$
v^{k}=v\left(w^{k}(a), r^{k}(a), a^{k}\right)=c \quad \forall k,
$$

where $v$ is the indirect utility function of a representative individual, $w^{k}$ are the wages, $r^{k}$ is the rental price of residential land, $l, a^{k}$ is an index of local amenities in location $k$ and $c$ is a 
constant. Utility increases in wages $\left(v_{w}>0\right)$ and decreases in rents $\left(v_{r}<0\right)$. It is also affected by the local amenities. The effect on utility of a change in local amenities depends on whether they are consumption amenities $\left(v_{a}>0\right.$, e.g. clean air) or disamenities $\left(v_{a}<0\right.$, e.g. noise $){ }^{3}$

Taking the total derivative of (1) and suppressing the superindices for notational simplicity yields:

$$
0=\frac{d v}{d a}=\frac{\partial v}{\partial w} \frac{d w}{d a}+\frac{\partial v}{\partial r} \frac{d r}{d a}+\frac{\partial v}{\partial a}
$$

By rearranging (2), we can obtain the implicit price of amenities as the ratio between marginal utilities, i.e. the marginal rate of substitution:

$$
\frac{\partial v}{\partial a} / \frac{\partial v}{\partial w}=-\left(\frac{\partial v}{\partial r} \frac{d r}{d a}\right) / \frac{\partial v}{\partial w}-\frac{d w}{d a}
$$

Equation (3) indicates that, when the HP equilibrium condition holds, both approaches, SWB and HP, could provide, in theory, the same marginal price for environmental amenities. Using SWB scores as a proxy for $v$, we can estimate equation (1) directly. A SWB regression on wages, amenities, and rents (and other controls) would yield estimates of the marginal utilities of the amenity $\partial v / \partial a$ and income $\partial v / \partial w$, which could be used to compute the left hand side of equation (3). On the other hand, the HP approach would provide an estimate of the right hand side of equation (3) by using housing and wage regressions to estimate $\mathrm{d} r / \mathrm{d} a$ and $\mathrm{d} w / \mathrm{d} a$, respectively. $^{4}$

\footnotetext{
${ }^{3}$ In our simple model, in order to illustrate the relationship between the HP and LS approaches we do not need to model the production side of the economy, including the production of housing. If we were to consider a non-traded good sector, housing, as in Roback (1982, Section II), the indirect utility function would depend on the price of housing as opposed to the rental price of residential land.

${ }^{4}$ Note that the term $-(\partial v / \partial r) /(\partial v / \partial w)$ can be equalized to the amount of residential land consumed, $l$, by Roy's identity.
} 
The equivalence of both methods implicit in (3) depends not only on the equilibrium condition but also on the specification of the SWB regression. In order to provide an estimate of the marginal utility of the amenity (that is, the partial derivative $\partial v / \partial a$ ), as opposed to the overall effect of a change in the amenity on utility (i.e. the total derivative $d v / d a$ ), other factors that compensate for changes in the amenity and that affect utility, in particular rents or housing prices, must be included in the regression. If they are omitted, then we would obtain an estimate of $d v / d a$ that, in equilibrium, by (2) should equal zero.

In disequilibrium, the individuals' utility is not equalized across locations and thus (1) does not hold. Consequently, the total variation in utility, $\mathrm{d} v / \mathrm{d} a$, is not equal to zero, and the marginal price of the amenity in this case would be given by the sum of the hedonic differentials and the residual term $(\mathrm{d} v / \mathrm{d} a) /(\partial v / \partial w)$ :

$$
\frac{\partial v}{\partial a} / \frac{\partial v}{\partial w}=-\left(\frac{\partial v}{\partial r} \frac{d r}{d a}\right) / \frac{\partial v}{\partial w}-\frac{d w}{d a}+\frac{d v}{d a} / \frac{\partial v}{\partial w}
$$

As it is clear from equation (4), in disequilibrium, the HP approach would provide biased estimates of the implicit price of amenities as the last term in the right hand side of equation (4), $(\mathrm{d} v / \mathrm{d} a) /(\partial v / \partial w)$, is ignored. However, as with equation (3), the left hand side of equation (4) could be derived directly from a SWB regression on amenities, wage and rents. If the SWB regression, however, were to omit other factors that compensate for the changes in the levels of amenities, we would obtain an empirical estimate of $\mathrm{d} v / \mathrm{d} a$ instead of $\partial v / \partial a$. This is the route taken by van Praag and Baarsma (2005) and Luechinger (2009). Given the existence of frictions in the housing market in their study areas, $\mathrm{d} v / \mathrm{d} a$ would be different from zero and can be estimated in a SWB regression. The LS and HP approaches in these papers are thus complementary methods, since with the LS approach they estimate the "residual" term $(\mathrm{d} v / \mathrm{d} a) /(\partial v / \partial w)$, i.e. the part of the externality that is not compensated for in the housing and 
labor markets. Note that, as a special case, if the amenity is not capitalized in private markets at all, that is if $(\mathrm{d} r / \mathrm{d} a)=(\mathrm{d} w / \mathrm{d} a)=0$, then from (4) $\mathrm{d} v / \mathrm{d} a=\partial v / \partial a$.

Our theoretical framework is general because it identifies how to use SWB data as a valuation tool independently of the equilibrium condition holding on private markets. The HP approach is based on strong assumptions of rationality, perfect information, instantaneous price adjustments, and no obstacles to the free mobility of individuals across different areas, which result in housing and labour markets perfectly compensating for differences in location-specific amenities. The valuation of local amenities elicited from individual choices on private markets might be biased in case of imperfections and bounded rationality (Freeman, 2003; Frey and Stutzer, 2005; Frey et al., 2004; Kahneman and Sugden, 2005). For example, if there are moving costs, the marginal WTP obtained from hedonic models for, say, an improvement in air quality will be biased downwards. The benefit people get from moving to a cleaner city ought to compensate them not only for the higher rents and lower income, but also for the cost of moving. By incorporating moving costs into their hedonic models, Bayer et al., (2009) obtain marginal WTP estimates that are three times larger than those estimated by a conventional hedonic model using the same data. In this context, an advantage of the LS approach is that it does not require the strong assumptions of rationality, perfect information and equilibrium in private markets, underlying revealedpreference methods.

Compared to conventional stated-preference methods, the LS approach might be able to capture to some extent the pure existence value of environmental goods and services (i.e., SWB might be affected by information regarding major events occurring far from the individual's dwelling area, such as a tsunami, extinction of large mammals, oil spills in marine natural parks, terrorism attacks, etc.). Evidence on this, however, is still scarce and contradictory. On one 
hand, Rehdanz (2007) finds a significant impact on LS of the number of bird and mammal species in the respondent's country and also in neighboring countries. On the other hand, a study by Berger (2008) using longitudinal German data finds that following the nuclear catastrophe of Chernobyl, environmental concern rose while LS changed little. This suggests that although people were aware of the severity of the catastrophe, their individual well-being was not affected by this global event.

Like HP, the LS approach avoids problems of strategic behaviour and lack of consideration of budget constraints and trade-offs among several substitutes reported in contingent valuation studies (Kahneman and Sugden, 2005). The relationship between public goods and SWB can be implicitly deduced without respondents being aware that their responses will be used to that end (Frey et al., 2004; Welsch, 2002, 2006).

The main caveat of the LS approach is related to the economic significance of self-reported well-being and its utilization as a proxy of the individual's indirect utility function. Despite a growing economics literature utilising SWB scores as a proxy for utility, this issue is still controversial. Clark et al. (2008) discuss at length whether there is a basis for believing that SWB is a reasonable measure of the economic notion of decision utility; i.e. the thing whose maximization leads to choice behaviour. This is particularly relevant for our study since the HP approach is based on maximizing choices in labor and housing markets. Clark et al. present support for the hypothesis that SWB is a good measure of utility in four areas. ${ }^{5}$ First, psychologists have been using SWB scores since the 1960s and there is now an extensive literature showing that SWB indices are reliable, consistent over time, valid and interpersonally comparable: happier people smile more; they are rated as such by friends and family and even by

\footnotetext{
${ }^{5}$ See Clark et al., 2008, Section 4 and references therein.
} 
individuals from other cultures. There is also a correlation between positive and negative states and neurological measures. Second, studies looking at LS have identified clear positive relations with factors considered important from a mainstream view of utility (income, marriage, job status, health and religion). Third, many panel data studies have found that SWB is a predictor of future behaviour (e.g. marital break-up) in that individuals choose to discontinue activities associated with low SWB. Fourth, factors important to explain LS (e.g. relative concerns) are also important for choice behaviour in controlled experiments.

Individuals, however, may make mistakes in predicting their SWB. Decision utility is an ex ante concept, but the hedonic experience that results from choice, i.e. experienced utility, is an ex post concept. SWB could still be experienced utility, i.e. the thing that people would want to maximize (Clark et al. 2008), but it may differ from decision utility. In order for there to be a general correspondence between decision and experienced utility, individuals must be capable of accurate affective forecasting. Because of underestimation of the extent of adaption to changed circumstances and because of the "focusing illusion" individuals forecasts of experienced utility are subject to systematic errors. Such errors induce preference anomalies in standard valuation methods based on decision utility that the experienced utility approach might circumvent (Kahneman and Sugden, 2005).

A problem with eliciting experienced utility via SWB responses is that they may suffer from biases typical of surveys such as, for example, question ordering and wording (see e.g., Bertrand and Mullainathan, 2001). In a recent paper, Krueger and Schkade (2008) study test-retest reliability of SWB and conclude that "while reliability figures for subjective well-being measures are lower than those typically found for education, income and many other microeconomic 
variables, they are probably sufficiently high to support much of the research that is currently being undertaken on subjective well-being" (p.1833).

In order to measure the effect of location-specific amenities on LS it is important that these are linked to the individual at the level at which she experiences them, i.e. at the local or regional levels. We argue that the utilization of GIS modelling to link location-specific attributes with the respondent's residence, and the associated high level of spatial disaggregation achieved, can help address this challenge in our SWB regression, especially when compared to previous crosscountry studies.

Finally, the valuation of intangibles using SWB scores requires the estimation of the marginal utility of income which, due to adaptation and aspiration effects and measurement error tends to be small leading to large estimated welfare measures. We come back to these issues when we discuss our empirical estimates and robustness checks in Section 5.

\section{Methodology}

\subsection{Testing the hedonic pricing equilibrium condition}

Using SWB scores as a proxy for individual's utility, we can test the equilibrium condition on which the HP approach is based. In order to perform such test, we could estimate the coefficients of the different components of equation (3) from wage and housing regressions and a comprehensive SWB regression on amenities, wages and rents to verify if the equality holds. ${ }^{6}$ However, implementing this test could be complicated. Unbiased hedonic differentials come

\footnotetext{
${ }^{6}$ However, note that a SWB regression on a given amenity as the only explanatory variable (i.e. excluding rents and wages) would capture the total effect of $a$ on utility ( $\mathrm{d} v / \mathrm{d} a)$, signaling the presence of equilibrium in the private markets if the coefficient on the amenity is not statistically different from zero. This is what is done in Stutzer and Frey (2004).
} 
from well-specified hedonic regressions in which all the relevant job and house characteristics are included as covariates. Moreover, in large scale, non-local, studies one might need to specify different hedonic regressions for each house and job market. ${ }^{7}$ This kind of data is rarely available or reliable.

In this paper we propose a straightforward test, by simply comparing SWB scores across locations. According to equation (1), the equilibrium condition holds if utility is equalized across locations. Using SWB is a proxy for indirect utility $\left(v^{k}\right)$, in statistical terms, the differences in reported SWB should not be significant across different locations. Under the assumption that personal traits are averaged out, we carried out parametric (ANOVA) and non-parametric (Kruskal-Wallis) statistical tests to investigate the significance of SWB differences across different geographical levels (regions, local authorities and electoral divisions) in Ireland.

In addition to these unconditional tests, we propose another, conditional, test to account for structural differences among locations as personal traits may not average out. We ran a SWB regression with location fixed effects $\delta_{k}, k=\{1, \ldots, K-1\}$, controlling for individual characteristics $\mathbf{x}$ :

$$
S W B_{i, k}=\alpha+\delta_{k}+\gamma^{\prime} \mathbf{x}_{i . k}+\varepsilon_{i, k} .
$$

and compute an F-test of joint significance of location fixed effects. Formally the null hypothesis of $\delta_{k}=0 \forall k$ is tested against the alternative that at least one location fixed effect is nonzero. That is, after controlling for individual characteristics, the null hypothesis is that there are no systematic differences in SWB across locations as captured in the location dummies.

\footnotetext{
${ }^{7}$ For example, in their study of the impact of proximity to hazardous waste sites on property values, Michaels and Smith (1990) found that it was unlikely that the relationship between equilibrium prices and homes' characteristics in Boston would be sufficiently described by a single hedonic price function.
} 


\subsection{Marginal and infra-marginal valuation of amenity changes}

From basic consumer theory we know that the marginal rate of substitution (MRS) between good $w$ and $a$ is the rate at which $w$ can be substituted for $a$ at the margin while holding the level of utility constant. If $w$ is wage and $a$ the level of a local amenity, the MRS between $a$ and $w$ yields the monetary value placed on a marginal change in the level of the amenity.

In order to obtain an estimate of their marginal utility, we need to expand (5) to include a vector of location specific amenities. In addition, since we are interested in the partial derivative $\partial v / \partial a$, as opposed to $\mathrm{d} v / \mathrm{d} a$, equation (6) includes wages and housing prices:

$$
S W B_{i, k}=\alpha+\delta_{k}+\beta_{1} \ln w_{i, k}+\beta_{2} \ln r_{i, k}+\gamma^{\prime} \mathbf{x}_{i . k}+\chi^{\prime} \mathbf{a}_{i, k}+v_{i, k}
$$

From (6), the implicit price for amenity $a$ evaluated at the mean wage $\bar{w}$, can be computed as:

$$
M R S=(\partial S W B / \partial a) /(\partial S W B / \partial w)=\chi \frac{\bar{w}}{\beta_{1}}
$$

Welfare economics suggests two additional monetary measures to account for the welfare effect of a discrete amenity change: (i) Compensating Surplus (CS) and (ii) Equivalent Surplus (ES). CS is the amount of money that would keep the individual at the original level of utility when a change in the provision of the amenity has occurred. ES is the amount of money that would move the individual to the new level of utility when a change in the provision of the amenity has not occurred (Freeman, 2003).

Since with the LS approach the indifference curve over $w$ and $a$ is estimated directly, the monetary value of infra-marginal amenity changes can also be estimated directly without any further assumptions related to weak-complementarity and the expenditure function (Perman et al., 2003 and Welsch, 2006). In other words, we do not need to estimate the Marshallian demand 
function and the related consumer surplus to get a monetary value of the welfare change (Bockstael and McConnell, 1993).

Consider an increase in the quality or the level of the amenity from $a^{1}$ to $a^{2}$ so that $a^{2}>a^{1}$ (e.g. a reduction of air and water pollution, a construction of schools or hospitals, etc.). We can compute the CS as the maximum WTP of individuals to secure the change in the provision of the amenity. This compensation equalizes individuals' utility (their SWB) before and after the change. Implicitly:

$$
\operatorname{SWB}\left(w, r, a^{l}\right)=\operatorname{SWB}\left(w-\mathrm{CS}, r, a^{2}\right) .
$$

Using the SWB regression specification in (6) and solving for CS at the mean wage, we obtain:

$$
\mathrm{CS}=-\exp \left[\ln (\bar{w})+\frac{\chi}{\beta_{1}}\left(a^{1}-a^{2}\right)\right]+\bar{w}
$$

Alternatively, we can look at the problem in terms of the ES, as the minimum amount of income that, were the change in the provision of the amenity not to occur, the individuals would need in order to reach the level of utility they would attain if the change took place.

$$
\mathrm{ES}=\exp \left[\ln (\bar{w})+\frac{\chi}{\beta_{1}}\left(a^{2}-a^{l}\right)\right]-\bar{w}
$$

\section{Data}

\subsection{Micro-level variables}

For the empirical analysis, data on individual's SWB and on socio-demographic and socioeconomic characteristics come from the Urban Institute Ireland National Survey on Quality of Life conducted in 2001, where a representative sample of 1,500 men and women, aged 18 and 
over and living in Ireland were interviewed. A detailed description of the survey can be found in the Appendix.

The SWB scores are based on the answers to the following question: "Thinking about the good and the bad things in your life, which of these answers best describes your life as a whole?". Respondents could choose a category on a scale of one to seven ('As bad as can be', 'very bad', 'bad', 'alright', 'good', 'very good', 'as good as can be'). The survey found high well-being in Ireland with an average of 5.47 on the seven-point scale (standard deviation = 0.98). Table 1 shows the average SWB scores by Local Authority area in Ireland. ${ }^{8}$ The lowest value is found in the East of Ireland, in Dublin South (4.68 with standard deviation of 1.16) and the highest in the West of Ireland, in Galway County (6.89 with a standard deviation of 0.31 ).

\section{- Table 1 about here -}

Demographic and socio-economic variables used in the analysis include age, gender, employment status (self employed, working part-time, working full-time, student, house keeper, unemployed), marital status (married, cohabiting, vs single/widowed), educational attainment (primary, lower secondary/junior high school, upper secondary/senior high school vs university degree) and family size. The survey's dataset did not contain a measure of wages, so we used

\footnotetext{
${ }^{8}$ The Republic of Ireland is divided into 8 regions (Regional Authorities) and 34 Local Authority areas for administrative purposes. The Regions coordinate certain activities of the local authorities and play a monitoring role in relation to the use of EU Structural Funds. The 8 regions are Dublin, Mid-East, South-East, South-West, MidWest, West and Border. The Local authorities equate to one body per county and one for the three major urban areas of Galway City, Limerick City and Cork City. Dublin is divided into four and Tipperary is divided into two local authority areas. Local authorities range in size from 2,035 hectares to 746,797 hectares (mean $=229,060$, standard deviation $=226,508)$, with total populations ranging from 25,799 individuals to 495,781 (mean $=177,377$, standard deviation $=135,990$ ) and population density ranging from 0.16 to 42 persons per squared $\mathrm{Km}$ (mean $=8.3$, standard deviation $=14)$.
} 
gross household income as a proxy. ${ }^{9}$ For house prices, we used the (log of) average house price of each individual's dwelling area (mainly corresponding with the respondent's electoral division) adjusted by the number of rooms. ${ }^{10}$ Table 2 reports the descriptive statistics of these variables by Irish region.

- Table 2 about here -

\subsection{Environmental variables}

Data on location-specific factors were linked to individuals' SWB and characteristics by matching the respondents' electoral division (ED) using GIS (as in Brereton et al., 2008), as it is recognized that at local level "the linkage between environment and happiness is even more articulate than it is with respect to national data" (Welsch, 2006 p. 11). The use of GIS modelling provides a methodological improvement over previous studies that have studied the impact of location-specific amenities on SWB. Such studies either control for one attribute only

\footnotetext{
${ }^{9}$ Missing values represented 23.7 percent of those interviewed and were imputed based on the respondent's sociodemographic characteristics including age, gender, marital status, education level, area inhabited and employment status. The original income variable was divided in 10 categories, so mid-points were used (as in Stutzer, 2004). The survey was carried out when Ireland was still using the Irish Pound, so we converted to Euros using the fixed rate of IR£1=€1.26974.
}

\footnotetext{
${ }^{10}$ The survey did not collect information on individual house prices. Thus house prices at the electoral district level were taken from the largest Irish property website (www.myhome.ie). Information on number of rooms was collected in the survey. Electoral Division (ED) is the smallest enumeration area used by the Irish Central Statistics Office in the collection of Census Data and it also represent the highest level of spatial disaggregation used in our survey. There are over 3,440 EDs in the Republic of Ireland. They are relatively small, particularly in the city regions. Those represented in our sample range in size from 18 hectares (in cities) to 6,189 hectares (open countryside $)($ mean $=1,767$, standard deviation $=1,538)$, with total populations ranging from 47 to 8,595 individuals (mean $=2,040$, standard deviation $=2,073)$ and population density ranging from 0.01 to 150 persons per $\mathrm{Km}^{2}\left(\mathrm{mean}^{2}\right.$ $=13.6$, standard deviation $=24)(\mathrm{CSO}, 2003)$.
} 
(for instance, perception of noise in van Praag and Baarsma, 2005) or they use macroeconometric SWB functions where each country is a cross-sectional unit (e.g. Welsch, 2006; Frey and Stutzer, 2005). Rehdanz and Maddison (2008) consider levels of noise and air pollution as perceived by the individuals in their sample. Linking respondents to their objective living circumstances at a very high level of disaggregation - the ED where the individual's dwelling is situated - can improve the analysis considerably by addressing an important dimension of individual heterogeneity: where the individual lives.

The set of location-specific amenities particularly relevant to our study includes climate variables, local air pollution and the presence of a waste facility (i.e., landfill) and coast within the respondent's ED. The climate variables are the January mean daily minimum air temperature, the July mean daily maximum air temperature and rainfall -measured as mean annual precipitation in millimetres, (from Collins and Cummins, 1996). Local air pollution data come from the Irish Environmental Protection Agency (EPA) and it is expressed in terms of annual mean ambient mass concentration of $\mathrm{PM}_{10}$ in micrograms per cubic meter (EPA, 2002). Pollution levels recorded in the monitoring stations were assigned to our observations on the basis of the proximity of the respondent's ED to the stations. There are eleven fixed monitoring stations and one mobile unit distributed across Ireland. In the case in which the respondent's ED was near to more than one monitoring station, a weighted average of the different values was attributed. ${ }^{11}$ As a measure of water quality we used proximity to seriously polluted river as

\footnotetext{
${ }^{11}$ We recognise that the number of monitoring stations may be low. However, it should be compared with the small population of Ireland (less than 4 million in 2001) and its size (68,883 sq. km). A comparison with recent literature using air pollution data from monitoring station provides evidence that the density of monitoring stations used in our study is not unusual. Luechinger (2009) uses data from 416 monitoring stations for the year 1994 and only 196 monitoring stations for the year 1985. Using the data for 1994 for conservative reasons, this translates into 0.000005 monitoring stations per inhabitant which is the same ratio found in Ireland. If we compare on the basis of land area,
} 
assessed by the EPA under the former National Rivers Monitoring Programme now replaced by the Water Framework Monitoring Programme (EPA, 2005). Table 3 shows the descriptive statistics of the environmental variables by region.

\section{- Table 3 about here -}

\section{Results}

\subsection{Testing for the equilibrium condition in the hedonic market}

With values ranging from 4.68 in Dublin South to 6.89 in Galway County, Table 1, reporting the average SWB scores in the 34 local authorities in Ireland, shows that there is some variation in the self-reported SWB among local authorities. The same can be said when the areas of reference are regions or EDs instead of the local authorities. In order to test whether these differences in reported SWB were statistically different, we carried out parametric and nonparametric statistical tests. The null hypothesis in these tests is that there are no differences between the mean self-reported SWB among different geographical areas in Ireland against the alternative hypothesis that there exist at least two locations where the SWB is different (Newbold et al., 2003).

The Bartlett's chi-squared statistic led to rejecting the assumption that the population variance of SWB is equal across regions, local authorities and EDs at $1 \%$ significance level (chi-square statistics equal to $38.6,227.42$ and 311.2 , respectively). In order to adjust for this, we used the non-parametric analog to the one-way ANOVA, namely the Kruskal-Wallis test, which led to the

in Germany there were 0.001 monitoring stations per square kilometres while there were 0.0001 monitoring stations in Ireland. However, the placing of the monitoring stations reflects population density with most of the fixed stations situated in the more populated eastern regions. 
rejection of the null hypothesis of equality of means across regions, local authorities and EDs at the $1 \%$ significance level (chi-square statistics equal to $38.2,407.7$ and 547.3 , respectively). ${ }^{12}$

Table 2 reports the descriptive statistics of the set of socio-demographic controls by region to show the spatial variation of these variables. To control for potential structural differences across regions, we performed a conditional test as detailed in Section 3.1. Equation (5) was estimated considering both local authorities and regions as fixed effects. Because the model with 7 region fixed effects is more parsimonious than the model with 33 local authority fixed effects, we present the results of the former, but the results of the latter are similar. The first column of Table 4 presents the coefficients of the region fixed effects estimated after an OLS regression of SWB on individual characteristics and region fixed effects. With an F-statistic $(7,99)$ equal to 5.31, the joint hypothesis of regional fixed effects equal to zero can be rejected at a 1 percent significance level. ${ }^{13}$ This test is in line with the results of the unconditional tests and confirms that even after controlling for individual characteristics, LS is significantly different across locations. The results are also robust to the OLS specification; the fixed effects were also significant when (5) was estimated using ordered probit. ${ }^{14}$

One may argue that the optimisation (and the choice of location) may occur at a household instead of at an individual level; therefore our test would not be appropriate because it uses individual LS and it does not consider the household as the locus of decision. In order to tackle

\footnotetext{
${ }^{12}$ Performing ANOVA led to the same conclusions (F-statistics for the test of the equality of SWB means equal 38.2 across regions, 19.05 across local authorities and 9.81 across EDs).

${ }^{13}$ When running OLS on local authority fixed effects, the null hypothesis can also be rejected at a 1 percent significance level $(\mathrm{F}$-statistic $(33,99)=50.59)$. The complete results are available upon request.

${ }^{14}$ Results from the Wald tests are Chi-square $(7)=38.53$ when using region fixed effects and Chi-square $(33)=$ 423.7 when using local authority fixed effects.
} 
this issue, we repeated the tests (both unconditional and conditional) for the subsample of individuals who lived alone. The Chi-squares from the non-parametric Kruskal-Wallis tests at the regional, local-authority and ED levels equal 198.4, 407.8 and 547.3 respectively, which lead to the rejection of the null in all cases. The coefficients of the regional fixed effects from the OLS estimation of equation (5) for this subsample are presented in the second column of Table 4. The F-statistic $(7,60)$ equals 4.89 , which leads to rejecting the null also in this case. ${ }^{15}$

It is worth noting that the outcome of our battery of tests unambiguously indicates that people living in the West of Ireland experience, ceteris paribus, a higher SWB than those living in other regions. Interestingly, people living in Dublin, the capital of the Republic and by far the largest city in Ireland, ${ }^{16}$ exhibit a lower SWB than those living elsewhere. This outcome is robust under any specification and in line with results in Brereton et al. (2008) and Moro et al. (2008).

\section{- Table 4 about here -}

The results of all the tests show that SWB varies significantly across locations in Ireland, indicating that utility is not equalized among different locations and thus, that the standard equilibrium condition in HP does not hold and that the value of the amenities is not fully compensated for by markets. ${ }^{17}$ In this case HP valuation cannot provide correct monetary

\footnotetext{
${ }^{15}$ These results are also robust to the ordered probit specification: Chi-square $(7)=30.26, p$-value $=0.000$.

16 The Dublin Region comprises four of the 34 local authority administrative areas (Dublin city, Dublin Fingal, Dun Laoghaire and South Dublin) and with a population of 1.122 million represents almost a third of the entire population of the Republic of Ireland (CSO, 2003).

${ }^{17}$ We run a further test by using the answers to a question reporting the satisfaction with the area in which the respondent lives instead of the answers to a general LS question as the dependent variable. The result of this test shows that satisfaction in this domain is not equalised across locations either $(F(7,99)=9.76$, $p$-value $=0.000$ for the test of equality of regional fixed effects).
} 
estimates of the value of environmental amenities. The next section estimates these values using the LS approach.

\subsection{Monetary Valuation}

\subsubsection{Baseline specification}

We estimated equation 6 and present the results of the baseline specification together with the monetary values associated with the environmental amenities statistically significant in the first column of Table 5. The estimates are derived from an OLS regression, but the results do not change when using ordered probit, as expected (see Ferrer-i-Carbonell and Frijters, 2004). ${ }^{18}$

Among the individual characteristics, unemployment, income and marital status affect SWB significantly. Being unemployed correlates strongly and negatively with SWB (-0.71 at a $1 \%$ significance level). Income has the expected positive sign and it is significant at the $1 \%$ level. Finally, as in Brereton et al. (2008), we found that being married is associated to a decrease in SWB. ${ }^{19}$

\footnotetext{
${ }^{18}$ All our econometric models are based on equation 6 and therefore include both (the log of) house prices and a set of environmental amenities as independent variables. In order to test for the potential multicollinearity between house prices and the amenities, we computed the Variance Inflation Factor (VIF) for house prices which was never larger than 1.33. A VIF greater than 10 is usually taken as indicative of a problem (Kennedy, 2003).

19 This result is counterintuitive and uncommon in the literature. We do not believe however that it is due to misspecification of our model (we control for household size, education, age and income) but rather to the social, cultural and political context surrounding divorce in Ireland in 2001. Among European countries, Ireland was the last one in allowing divorce in 1997, and until 2003 unilateral divorces (i.e. divorces not requiring mutual consent and granted at the request of either spouse) were not allowed. The rate of divorce for the period 1990-2003 in Ireland was 0.63 per thousand married people, the lowest in Europe and compares to an average of 4.23 divorces (std dev 2.02) per thousand marriages (Gonzalez and Viitanen, 2009). We hypothesise that as of 2001 some people in Ireland could have been 'trapped' in unhappy marriages.
} 
As for the environmental variables, the coefficient on January minimum temperature is positive and significant at a $1 \%$ level, indicating preferences for warmer climate in winter (one additional degree of temperature in January temperature would increase the SWB by about 0.5 points on our cardinal SWB scale). The coefficient on July maximum temperature is also positive and significant, implying a preference towards warmer temperature in summer. A raising in July temperature by one degree would increase the SWB by about 0.2 points. These results are consistent with a recent study by Rehdanz and Maddison (2005) analyzing the effect of climate on SWB. They find that "modest global warming with higher winter temperatures would increase people's happiness, particularly, for those living in the North. Those living in regions already characterized by very high temperatures would lose out” (p. 120).

Being exposed to local air pollution in terms of mass concentration of $\mathrm{PM}_{10}$ significantly reduces individual's well-being (the coefficient is -0.033). This translates into a loss of 0.75 points in SWB if the annual mean concentration were to increase by $150 \%$ (which corresponds to $50 \mu \mathrm{g} / \mathrm{m}^{3}$, the maximum value which should not be exceeded more than 35 times a year according to Directive 1999/30/EC).

\section{- Table 5 about here -}

In order to assess the monetary values of these environmental factors we computed their MRS with income according to equation (7), using the estimated coefficients from the first column of Table 5. The shadow cost for $\mathrm{PM}_{10}$, computed in this way, is $€ 945$ per microgram per cubic meter, which is comparable to the estimates of Welsch (2006) for lead and $\mathrm{NO}_{2}$ The average individual in our sample would be willing to pay this amount for a one-unit decrease (one microgram per cubic meter -which is an improvement of $5 \%$ over the average value) in air pollution. We obtained a high marginal price, $€ 15,585$, for an additional degree of temperature 
in January, and $€ 5,759$ for an improvement of July temperature. Previous studies also find large values. A recent study from Rehdanz and Maddison (2005) shows that households in Germany are willing to pay an amount ranging from 2,250 euro to 3,560 euro for a one degree centigrade increase in January temperature. By contrast, estimates of the marginal WTP for July temperatures range from 4,162 euro to 6,661 euro to avoid a one degree centigrade increase. See also Maddison and Bigano (2003) for a similar hedonic study conducted for Italy.

In addition, we estimated the equivalent/compensating surpluses for discrete changes in January and July temperatures and $\mathrm{PM}_{10}$ concentrations. For example, an individual would be willing to pay around $€ 4,200$ to experience an increase in January minimum temperature from $2.3^{\circ} \mathrm{C}$ (the average January minimum temperature in Ireland) to $2.6^{\circ} \mathrm{C}$ (i.e., the average minimum January temperature in the Dublin Region) and about $€ 1,600$ for an increase in July maximum temperature from $19.2^{\circ} \mathrm{C}$ (i.e., the average July maximum temperature in the Country) to $19.5^{\circ} \mathrm{C}$ (i.e., the average July maximum temperature around the Dublin Region). These changes translate into different ES (i.e., the minimum amount of income that the same individual would need in order to attain the higher level of utility he would have reached if the changes were not to occur). For the same changes in January minimum temperature and July maximum temperature the ES would be equal to about $€ 5,200$ and $€ 1,800$, respectively. Because $\mathrm{PM}_{10}$ is a disamenity, the monetary values enter the table with a negative sign. An individual would be willing to accept about $€ 3,200$ for an increase in $\mathrm{PM}_{10}$ from $20.4 \mu \mathrm{g} / \mathrm{m}^{3}$ (the Irish annual average) to 23.6 $\mu \mathrm{g} / \mathrm{m}^{3}$ (the annual average registered in the Dublin Region) and he would be willing to pay around $€ 2,800$ for the same change not to occur. 


\subsubsection{Robustness checks}

It can be argued that in disequilibrium situations, HP estimates are biased while the monetary estimates computed using the LS approach incorporate the residual part of the externality not accounted for in private markets. Nevertheless, the monetary values reported in the bottom rows of Table 5, seem too large. In columns 2-6 of Table 5 we report results from different specifications to check whether the estimates are robust to further spatial controls and to different specifications of the income variable.

In an attempt to control for additional location-specific factors, and, in particular, variables that may be correlated with pollution, we expanded the list of amenities to include distances to urban centres and transport infrastructures. ${ }^{20}$ The inclusion of two variables capturing whether the individual's ED is located within $5 \mathrm{Km}$ from an urban centre and major roads in the second column of Table 5 affects the estimates of mean annual concentration of $\mathrm{PM}_{10}$, that stops being significant, as $\mathrm{PM}_{10}$ concentration are correlated with urban amenities (the correlation coefficient between urban centres and $\mathrm{PM}_{10}$ is 0.57 ). The point estimates for the MRS drops to $€ 615$ while the CS and ES drop to $€ 2055$ and $€ 1887$, respectively, although these are not statistically different from the baseline at a $90 \%$ confidence level. The coefficients and monetary estimates for the January min temperature variable are robust to the inclusion of these variables, while those for July max temperature slightly increase.

\footnotetext{
${ }^{20}$ The Local Government Act of 2001 legally defines five cities in Ireland: Dublin, Limerick, Cork, Galway and Waterford. In these cities the population is at least greater than 40,000 inhabitants (CSO, 2007). The Roads Act 1993 Order 2006 lists the primary and secondary roads in Ireland. We use this classification to build a network of major roads. We use a buffer area of $5 \mathrm{Km}$ as this is defined as the "ideal" distance from a major road in the National Spatial Strategy (see http://www.irishspatialstrategy.ie/pdfs/Sec5a.pdf ). The correlation coefficients of urban areas and proximity to major roads with $\mathrm{PM}_{10}$ are 0.57 and 0.39 , respectively.
} 
Expanding the list of regressors further to include population density and crime rate (third column of Table 5) does not alter the coefficients and monetary values attached to January and July that confirm to be robust across specifications, both statistically and economically, while the monetary values associated to $\mathrm{PM}_{10}$ decrease further (for example, the MRS is equal to $€ 328$ ). ${ }^{21}$ Of the new variables, crime rate has a negative and significant impact (at the $10 \%$ significance level) on LS.

While large monetary estimates for intangibles are not uncommon in the economics of happiness literature, ${ }^{22}$ we believe that they may be due, in part, to a common but overlooked issue associated with the cardinalisation of utility when using SWB as a valuation tool: a small estimated coefficient for the marginal utility of income. We believe that two factors may help explaining such small figures: biases in the income variable and comparison (adaptation/aspiration) effects.

The first problem includes measurement errors in the income variable used in the analysis. In our study, as in most cases, gross household income is given in intervals, it is self-reported and missing values were imputed. This may bias its estimated coefficient downwards. Regarding the second problem, while an increase in income initially provides extra pleasure, this effect is usually only transitory (Easterlin, 2001; Stutzer, 2004). There is a large literature now showing that absolute income may not affect SWB because people tend to compare with their past

\footnotetext{
${ }^{21}$ Population density was computed at ED level using data from Census 2002 (CSO, 2003), while crime rate consists of number of headline crimes in the respondent's local authority area per 100,000 population (Garda Siochana, 2001). The correlation coefficients of these variables with $\mathrm{PM}_{10}$ are both 0.56 .

${ }^{22}$ For example, Blanchflower and Oswald (2004) found that a rise in income of $\sim \$ 60,000$ per annum (above and beyond the income loss associated with unemployment) would be required to 'compensate' men for unemployment and that a "lasting marriage" is worth $\$ 100,000$ per annum.
} 
situations or their peers. It is 'relative' income that matters (see, e.g. Clark et al., 2008; Ferrer-iCarbonell, 2005; Mentzakis and Moro, 2008). SWB regression on absolute income captures mainly the marginal utility after adaptation (the long-run marginal utility). Therefore, the utility consequences of changes in income may be underestimated. This effect would also bias the estimated welfare measures upwards. ${ }^{23}$ We included several measures of relative income but they were not statistically significant and were dropped from the final specification. ${ }^{24}$

The last three columns of Table 5 test the robustness of our results to changes in the measurement of the income variable. The fourth column of Table 5 shows what happens when self-employed people are excluded from the sample, following the hypothesis that incomes in this category are more likely to be misreported (Luechinger 2009). The results in this column are in line with those of our baseline model. In brief, the monetary values tend to be smaller but not statistically different -at a 90 percent confidence level- from the baseline.

As with the test of the equilibrium condition, to address the issue of using household-level variables to explain individual LS, we ran a SWB regression reducing the sample to one-person households for which household and individual variables (in particular income) coincide. Although the number of observation drops significantly $(N=162)$ the results are comparable to those in the baseline. The coefficient of January temperature in the SWB regression is robust, the coefficient on $\mathrm{PM}_{10}$ increases in size and significance and while July temperature stops being

\footnotetext{
${ }^{23}$ Kahneman and Sudgen (2005) note that adaptation is not universal. There are some pleasures and pains to which people do not adapt. For example, people tend not to adapt to pain. Of more relevance to this paper, evidence (albeit scarce) seems to indicate that people may not adapt to environmental disamenities. For example, people do not adapt to noise (Cohen et al. 1981; Weinstein 1982).

${ }^{24}$ The measure of relative income was computed as the difference between one's own income and the average income of the local authority of residence. It was not significant perhaps because our sample is not large enough.
} 
statistically significant, its estimated coefficient does not change substantially. The monetary values for January and July temperature are smaller (for example, their MRS are around $€ 7,300$ and $€ 2,800$, respectively, roughly half of those in the baseline model), although they are not statistically different from those in the baseline regression, while for $\mathrm{PM}_{10}$ they are comparable in size.

We also analyzed the robustness of the results to using an instrument for the income variable. Endogeneity of income is a common problem in this literature. Happy people earn more and unobserved factors may lead to both greater LS and higher income. In addition, income generation is associated to costs such as working hours, stress, health risks, etc. that are difficult to control for. Omission of such factors induces downward bias in the income estimates. We attempted to reduce this problem by running a further model in which the log of the original household income variable is instrumented using social class. At the end of each interview, the interviewer was asked to assign a social class to the respondent on the basis of the information collected using a classification defined by the national statistics office of Ireland. Social class is an ordinal variable which takes a value of 1 for the highest social class and 6 for the lowest. ${ }^{25}$

\footnotetext{
${ }^{25}$ The social classes are identified on the basis of the broad occupation: professional, managerial and technical, non-manual, skilled manual, semi-skilled and unskilled workers (see http://www.cso.ie/census/documents/saps cop 2002.pdf). In order to assess the validity of social class as an instrument for income, we first checked whether income and social class are correlated. The coefficient of social class in the first stage regression equals -0.29 (recall that social class goes from highest to lowest social class) with a p-value equal to $0.000(\mathrm{R}$-square $=0.34 ; \mathrm{F}(1,85)=79.18)$. With only one instrument for income, our model is exactly identified and we cannot test for the exogeneity of social class. However, we can check whether social class has an impact on LS independently of income. We did that by adding social class to our LS regression (that includes income). Social class was not significant at any standard level of significance ( $p$-value $=0.57 ; F(1,85)=0.32$ ). In the same line, we included the residuals from a regression of social class on log of household income into our baseline LS regression. The coefficient on the residuals $(-0.009$ with $p$-value $=0.79)$ indicates that they are not correlated with LS.
} 
The results of the IV regression are shown in the last column of Table 5. The coefficients on $\mathrm{PM}_{10}$ and January temperature are robust under this specification too, while July temperature is not statistically significant. The monetary values for $\mathrm{PM}_{10}$ and January generated from this model are comparable with the baseline, although in this case they are larger.

\section{Conclusion and Further Research}

This paper presents a comprehensive theoretical and methodological framework for the valuation of environmental and other location-specific amenities using subjective well-being data. In doing so, we clarify the ties between this method and standard environmental valuation techniques, in particular hedonic pricing. We show that the relationship between the two methods depends on whether the location market is in equilibrium and on the specification of the happiness function.

When wages and housing prices fully adjust to equalize utility across locations (i.e. the location market is in equilibrium), we show that both approaches could, in theory, provide the same marginal price for environmental amenities. When the location market is out of equilibrium estimates from hedonic regressions are biased. Happiness regressions can provide an estimate of the (full) value of the amenity if they include other factors that compensate for changes in the amenity and that affect utility, in particular rents or housing prices. If these compensating factors are omitted, we would obtain an estimate of the part of the externality not compensated for in hedonic markets.

In the paper we also show how life satisfaction scores could be used to test for the equilibrium condition required by the hedonic pricing approach in a straightforward way, which does not require information from housing or labour markets. 
In our empirical application we use self-reported well-being to compute the implicit price of a range of local environmental amenities in Ireland. By using highly spatially disaggregated data (we use GIS to link environmental attributes to each respondent) we attempt to capture the effects of local and regional factors which are not captured in previous cross-country studies.

The factors identified by our model as affecting individuals' subjective well-being in Ireland are warmer temperatures, and local mass concentration of $\mathrm{PM}_{10}$. Overall, the impacts of these environmental attributes on utility are large and result in large monetary estimates. We argue, however, that there could be an upward bias in these monetary estimates resulting from a small estimated marginal utility of income used in their calculation. A series of alternative regressions in which we expand the set of controls and use different specifications for income, show that the results are robust in terms of statistical significance and direction of the effects (especially for January minimum temperature and $\mathrm{PM}_{10}$ concentration), and that the size of the point estimates is always large, even when we instrument for income.

An in-depth investigation on the economic meaning of the relationship between subjective well-being as a proxy for long-run experienced utility and income is beyond the scope of this paper, but further results from this active area of research are of critical importance to the use of SWB data for environmental valuation. It is important to point out that, although the upward biases in the implicit values associated with measurement errors, endogeneity in the income variable and comparison effects, would lead to caution in the interpretation of the figures obtained using the life-satisfaction approach as upper-bound estimates, none of these caveats are present in the use of SWB scores to test for the hedonic-pricing equilibrium condition. Moreover, SWB still offers valuable insights when assessing which environmental variables may be relevant in evaluating the quality of life of societies. 


\section{Appendix}

\section{The survey}

The Urban Institute Ireland National Survey on Quality of Life was conducted in 2001 where a representative sample of 1,500 men and women, aged 18 and over and living in Ireland where interviewed. The survey contains data on individual's SWB, socio-demographic and socioeconomic characteristics and a location-identifier, the electoral district of each respondent.

Due to missing observations the final sample consists of approximately (depending on the model specification) 1,467 observations. The effective response rate is 66.6 percent. The margin of error using the entire sample is \pm 2.5 percent at a 95 percent confidence level.

The 2000 Register of Electors was used as the sampling frame. The register is inclusive of all individuals nominated on Electoral Registration forms returned in July 2000. The register is compiled on a Local Authority basis of which there are 34 in Ireland. The sampling procedure adopted was a two stage proportionate random sampling procedure using probability proportionate to size (PPS). The rationale governing this choice of design was to ensure coverage of all 34 Local Authority areas with proportionate representation of all the areas. In selecting potential respondents from each, a computerized random numbers procedure was again used to ensure that each elector listed had an equal chance of being selected.

All interviews were conducted during the period 12 March 2001 to 25 May 2001. To test for non-response bias, four key variables from the sample (age, sex, marital status and economic activity) were compared with corresponding Irish census estimates. Given the broad representativeness of the sample, no corrective weighting procedures were applied to the data (see Urban Institute Ireland National Survey on Quality of Life, UII, 2001). 


\section{References}

Bateman, I., Carson, R. T., B., D., Hanemann, M., Hanley, N., Hett, T., Jones-Lee, M., Loomes, G., Mourato, S., Ozdemiroglu, E., Pearce, D. W., Sugden, R. and Swanson, J. (2002). Economic Valuation with Stated Preference Techniques. Cheltenham: Edward Elgar.

Bayer, P., N. Keohane and C. Timmins (2009) Migration and hedonic valuation: The case of air quality. Journal of Environmental Economics and Management 58(1):1-14

Bertrand, M. and Mullainathan, S. (2001). Do People Mean What They Say? Implications for Subjective Survey Data. American Economic Review 91, 67-72.

Blanchflower, D. G. and Oswald, A. J. (2004). Well-being over time in Britain and the USA. Journal of Public Economics 88, 1359-1386.

Blomquist, G.C., Berger, M.C and Hoehn, J.P. (1988). New estimates of quality of life in urban areas. American Economic Review 78 (1), 89-107.

Bockstael, N. E. and McConnell, K. E. (1993). Public Goods as Characteristics of Non-Market Commodities. The Economic Journal 103, 1244-1257.

Brereton, F., Clinch, J. P. and Ferreira, S. (2008). Happiness, geography and the environment. Ecological Economics 65, 386-396. 
Clark, A. E., Frijters, P. and Shields, M. A. (2008). Relative Income, Happiness and Utility: An Explanation for the Easterlin Paradox and Other Puzzles. Journal of Economic Literature $46,95-144$.

Cohen, S., G. W. Evans, D.S Krantz, D. Stokols and S. Kelly (1981), "Aircraft Noise and Children: Longitudinal and Cross-Section Evidence on Adaptation to Noise and the Effectiveness of Noise Abatement” J. Personality and Social Psychology 40, 331-45.

Collins, J. F. and Cummins, T. (1996). Agroclimatic Atlas or Ireland. Dublin, Ireland: University College Dublin, UCD.

Costa, P. T. and McCrae, R. R. (1988). Personality in adulthood: A six-year longitudinal study of self-reports and spouse ratings on the NEO Personality Inventory. J Personality and Social Psychology 54, 853-863.

CSO (2003). Census 2002. (Central Statistical Office) Dublin, Ireland: Stationary Office.

Di Tella, R. and MacCulloch, R. (2006). Some Uses of Happiness Data in Economics. Journal of Economic Perspectives 20, 25-46.

Diener, E. (1984). Subjective well-being. Psychological Bulletin 95, 542 - 575. .

Diener, E. and Lucas, R. E. (1999). Personality and Subjective Well-Being. In Foundations of Hedonic Psychology: Scientific Perspectives on Enjoyment and Suffering, Vol. Chapter 11 (Eds, Kahneman, D., Diener, E. and Schwarz, N.). New York: Russel Sage Foundation. 
Diener, E., Suh, E. M., Lucas, R. E. and Smith, H. L. (1999). Subjective Well-Being: Three Decades of Progress. Psychological Bulletin 125, 276-302.

Dixon, H. D. (1997). Controversy: Economics and Happiness Editorial Note. Economic Journal 107: $1812-14$

Easterlin, R. A. (1973). Does Money Buy Happiness? The Public Interest 30, 3-10.

Easterlin, R. A. (1974). Does Economic Growth Improve the Human Lot? In Nation and Households in Economic Growth: Essays in Honour of Moses Abramovitz(Eds, David, P. A. and Reder, M. W.). New York: Academic Press.

Easterlin, R. A. (2001). Income and Happiness: Towards a Unified Theory. Economic Journal $111,465-484$

EPA (2002). Air Quality Monitoring Annual Report 2001. Dublin, Ireland: Environmental Protection Agency.

EPA (2005). Water Quality in Ireland 2001-2003. Wexford, Ireland: Environmental Protection Agency.

EPA (2005). National Waste Database, Wexford, Ireland: Environmental Protection Agency.

Fernandez-Dols, J.-M. and Ruiz-Belda, M.-A. (1995). Are smiles a sign of happiness? Gold medal winners at the Olympic Games. J. Personality and Social Psychology 69: 1113-19. 
Ferrer-i-Carbonell, A. and P. Frijters (2004) "How important is methology for the estimates of the determinants of happiness?" Economic Journal 114(497): 641-59.

Ferrer-i-Carbonell, A. (2005). Income and well-being: an empirical analysis of the comparison income effect. Journal of Public Economics 89, 997-1019.

Freeman, M. A. (2003). The measurement of environmental and resource values: theory and methods. Washington DC: Resources for the Future

Frey, B., Luechinger, S. and Stutzer, A. (2004). Valuing Public Goods: The Life Satisfation Approach. CESifo Working Paper Series no. 1158.

Frey, B. and Stutzer, A. (2005). Happiness Research: State and Prospects. Review of Social Economy 63, 207-228.

Frey, B. S. and Stutzer, A. (2002). What Can Economists Learn from Happiness Research? Journal of Economic Literature 40, 402-435.

Frijters, P. and van Praag, B.M.S. (1998). The Effects of Climate on Welfare and Well-being in Russia. Climate Chage 39, 61-81.

Garda Siochana (2001) Annual Report, Garda Siochana, Dublin.

Gonzalez, L. and T. K. Viitanen (2009) "The effect of divorce laws on divorce rates in Europe" European Economic Review 53(2): 127-38. 
Hanley, N., Mourato, S. and Wright, R. E. (2001). Choice Modelling Approaches: A Superior Alternative for Environmental Valuation? Journal of Economic Surveys 15, 435-62.

Kahneman, D. and Sugden, R. (2005). Experienced utility as a standard of policy evaluation. Environmental and Resource Economics 32, 161-181.

Kahneman, D., Wakker, P. P. and Sarin, R. (1997). Back to Bentham? Explorations of Experienced Utility. The Quarterly Journal of Economics 112, 375-405.

Kennedy, P. (2003). A guide to econometrics. The MIT Press: Cambridge, Massachussets.

Krueger, A. B. and Schkade, D. A. (2008). The reliability of subjective well-being measures. Journal of Public Economics 92, 1833-1845.

Luechinger, S. (2009). Valuing air quality using the life satisfaction approach. The Economic Journal, 119 (March): 482-515.

Maddison, D. and Bigano, A. (2003). The Amenity Value of the Italian Climate. Journal of Environmental Economics and Management 45, 319-332.

Mentzakis, E. and Moro, M. (2008). The Poor, the rich and the happy: exploring the link between subjective well-being and income. Journal of Socio-Economics.

Michaels, R. G. and V. K. Smith (1990) Market segmentation and valuing amenities with hedonic models: The case of hazardous waste sites. J Urban Economics 28(2): 223-42. 
Moro, M., Brereton, F., Ferreira, S. and Clinch, J. P. (2008). Ranking quality of life using subjective well-being data. Ecological Economics 65, 448-460.

Newbold, P., Carlson, W. L. and Thorne, B. M. (2003). Statistics for Business and Economics. Pearson Prentice Hall.

Ng, Y.-K. (1997). A Case for Happiness, Cardinalism, and Interpersonal Comparability. Economic Journal 107, 1848-1858.

Nolan, B and Maitre, B. (2000). A Comparative Perspective on Trends in Income Inequality in Ireland. The Economic and Social Review, 31(4), 329-350.

Perman, R., Ma, Y., McGilvray, J. and Common, M.S. (2003). Natural resource and environmental economics. Harlow, Essex: Pearson Education.

Rehdanz, K. and Maddison, D. (2005). Climate and happiness. Ecol Econ 52, 111-25.

Rehdanz, K. and Maddison, D. (2008). Local Environmental Quality and Life Satisfaction in Germany. Ecol Econ 64: 787-97.

Roads Act 1993, Classification of National Roads, Order 2006. http://www.irishstatutebook.ie/1993/en/act/pub/0014/index.html

Roback, J. (1982). Wages, Rents, and the Quality of Life. J Polit Econ 90, 1257-1278.

Rosen, S. (1974). Hedonic Prices and Implicit Markets: Product Differentiation in Pure Competition. J Polit Econ 82, 34-55. 
Sandvik, E., Diener, E. and Seidlitz, L. (1993). Subjective Well-Being: The Convergence and Stability of Self-Report and Non-Self-Report Measures. J of Personality 61, 317-342.

Smith, V.K. (2008). Reflections on the literature. Review of Environmental Economics and Policy 2(2):292-308

Stutzer, A. (2004). The role of income aspirations in individual happiness. Journal of Economic Behavior \& Organization 54, 89-109.

Stutzer, A. and Bruno, S. F. (2004). Stress That Doesn't Pay: The Commuting Paradox. Institute for the Study of Labor (IZA).

UII (2001). Urban Institute Ireland National Survey on Quality of Life. Dublin: Urban Institute Ireland.

van Praag, B. (1971). The welfare function of income in Belgium: An empirical investigation. European Economic Review 2, 337-369.

van Praag, B., M. S. and Baarsma, B. E. (2005). Using Happiness Surveys to Value Intangibles: The Case of Airport Noise. Economic Journal 115, 224-246.

Weinstein, N.D. (1982), “Community Noise Problems: Evidence Against Adaptation” Journal of Environmental Psychology 2: 87-97.

Welsch, H. (2002). Preferences over Prosperity and Pollution: Environmental Valuation Based on Happiness Surveys. Kyklos 55, 473-494. 
Welsch, H. (2006). Environment and happiness: Valuation of air pollution using life satisfaction data. Ecological Economics 58, 801-813.

Table 1. Average SWB scores by Local Authority Area in Ireland (2001)

\begin{tabular}{|c|c|c|c|c|}
\hline Local Authority & Mean SWB & Std. Dev. SWB & Freq. & $\%$ \\
\hline Galway County & 6.89 & 0.31 & 56 & $3.8 \%$ \\
\hline Tipperary South & 6.79 & 0.55 & 33 & $2.3 \%$ \\
\hline Galway City & 6.67 & 0.80 & 21 & $1.4 \%$ \\
\hline Wicklow & 6.37 & 0.86 & 41 & $2.8 \%$ \\
\hline Limerick City & 6.05 & 0.71 & 19 & $1.3 \%$ \\
\hline Mayo & 5.90 & 0.98 & 42 & $2.9 \%$ \\
\hline Offaly & 5.84 & 0.94 & 25 & $1.7 \%$ \\
\hline Leitrim & 5.75 & 1.06 & 12 & $0.8 \%$ \\
\hline Kerry & 5.74 & 0.56 & 53 & $3.6 \%$ \\
\hline Limerick County & 5.73 & 0.57 & 51 & $3.5 \%$ \\
\hline Meath & 5.72 & 0.46 & 39 & $2.7 \%$ \\
\hline Waterford City & 5.71 & 1.38 & 7 & $0.5 \%$ \\
\hline Dublin Fingal & 5.63 & 0.60 & 64 & $4.4 \%$ \\
\hline Kilkenny & 5.63 & 0.61 & 30 & $2.1 \%$ \\
\hline Carlow & 5.60 & 1.27 & 20 & $1.4 \%$ \\
\hline Cork County & 5.54 & 1.05 & 116 & $7.9 \%$ \\
\hline Louth & 5.51 & 0.68 & 39 & $2.7 \%$ \\
\hline Wexford & 5.51 & 0.82 & 45 & $3.1 \%$ \\
\hline Laois & 5.45 & 0.69 & 20 & $1.4 \%$ \\
\hline Cork City & 5.43 & 1.04 & 51 & $3.5 \%$ \\
\hline Tipperary North & 5.38 & 0.73 & 29 & $2.0 \%$ \\
\hline Clare & 5.36 & 0.57 & 47 & $3.2 \%$ \\
\hline Roscommon & 5.32 & 0.78 & 22 & $1.5 \%$ \\
\hline Longford & 5.27 & 0.47 & 11 & $0.8 \%$ \\
\hline Monaghan & 5.26 & 0.75 & 23 & $1.6 \%$ \\
\hline Donegal & 5.25 & 0.84 & 52 & $3.6 \%$ \\
\hline Westmeath & 5.23 & 0.95 & 26 & $1.8 \%$ \\
\hline Dun Laoigaire & 5.21 & 0.79 & 81 & $5.5 \%$ \\
\hline Cavan & 5.21 & 0.78 & 24 & $1.6 \%$ \\
\hline Kildare & 5.16 & 0.78 & 64 & $4.4 \%$ \\
\hline Sligo & 5.13 & 0.76 & 31 & $2.1 \%$ \\
\hline Dublin City & 4.76 & 0.95 & 165 & $11.3 \%$ \\
\hline Waterford County & 4.76 & 0.44 & 21 & $1.4 \%$ \\
\hline Dublin South & 4.68 & 1.16 & 80 & $5.5 \%$ \\
\hline Overall Ireland & 5.47 & 0.98 & 1460 & $100 \%$ \\
\hline
\end{tabular}


Table 2. Descriptive statistics of micro-level variables

\begin{tabular}{|c|c|c|c|c|c|c|c|c|c|}
\hline & Ireland & Dublin & Mid-East & South East & South West & Mid-West & Border & Midland & West \\
\hline \multicolumn{10}{|l|}{ Gender } \\
\hline Female & $48 \%$ & $55 \%$ & $56 \%$ & $51 \%$ & $54 \%$ & $52 \%$ & $47 \%$ & $49 \%$ & $48 \%$ \\
\hline Male & $52 \%$ & $45 \%$ & $44 \%$ & $49 \%$ & $46 \%$ & $48 \%$ & $53 \%$ & $51 \%$ & $52 \%$ \\
\hline \multicolumn{10}{|l|}{ Age } \\
\hline $\mathrm{N}$ & 1492 & 391 & 145 & 160 & 229 & 146 & 184 & 81 & 141 \\
\hline Mean & 43.6 & 43.4 & 39.4 & 43.3 & 43.1 & 40.6 & 46.5 & 42.7 & 50.3 \\
\hline Std. Deviation & 17.1 & 16.7 & 15.7 & 16.5 & 17.8 & 15.5 & 18.4 & 18.1 & 16.1 \\
\hline Min & 18 & 18 & 18 & 18 & 18 & 18 & 18 & 18 & 19 \\
\hline Max & 90 & 87 & 82 & 84 & 88 & 86 & 89 & 90 & 87 \\
\hline \multicolumn{10}{|l|}{ Education level } \\
\hline $\mathrm{N}$ & 1500 & 381 & 135 & 161 & 218 & 142 & 178 & 79 & 142 \\
\hline Primary & $17 \%$ & $17 \%$ & $10 \%$ & $6 \%$ & $10 \%$ & $6 \%$ & $30 \%$ & $18 \%$ & $13 \%$ \\
\hline Lower Secondary & $19 \%$ & $23 \%$ & $31 \%$ & $22 \%$ & $14 \%$ & $5 \%$ & $15 \%$ & $14 \%$ & $28 \%$ \\
\hline Upper Secondary & $47 \%$ & $48 \%$ & $40 \%$ & $65 \%$ & $57 \%$ & $46 \%$ & $37 \%$ & $48 \%$ & $46 \%$ \\
\hline Others & $1 \%$ & $4 \%$ & $9 \%$ & $4 \%$ & $7 \%$ & $20 \%$ & $8 \%$ & $6 \%$ & $8 \%$ \\
\hline Degree/ Post degree & $16 \%$ & $9 \%$ & $10 \%$ & $4 \%$ & $12 \%$ & $23 \%$ & $10 \%$ & $14 \%$ & $5 \%$ \\
\hline \multicolumn{10}{|l|}{ Marital Status } \\
\hline $\mathrm{N}$ & 1489 & 392 & 145 & 161 & 231 & 147 & 184 & 82 & 142 \\
\hline Married & $55 \%$ & $52 \%$ & $51 \%$ & $50 \%$ & $48 \%$ & $57 \%$ & $49 \%$ & $57 \%$ & $56 \%$ \\
\hline Single & $35 \%$ & $34 \%$ & $36 \%$ & $33 \%$ & $41 \%$ & $39 \%$ & $37 \%$ & $26 \%$ & $33 \%$ \\
\hline Cohabit & $2 \%$ & $2 \%$ & $4 \%$ & $3 \%$ & $3 \%$ & $1 \%$ & $2 \%$ & $2 \%$ & $1 \%$ \\
\hline Separated/divorced & $3 \%$ & $4 \%$ & $3 \%$ & $6 \%$ & $2 \%$ & $0 \%$ & $2 \%$ & $5 \%$ & $4 \%$ \\
\hline Widowed & $7 \%$ & $8 \%$ & $6 \%$ & $7 \%$ & $6 \%$ & $3 \%$ & $10 \%$ & $10 \%$ & $6 \%$ \\
\hline \multicolumn{10}{|l|}{ Family size } \\
\hline $\mathrm{N}$ & 1487 & 388 & 144 & 154 & 231 & 146 & 184 & 82 & 142 \\
\hline Mean & 3.4 & 3.4 & 3.6 & 3.0 & 3.6 & 3.6 & 3.3 & 3.6 & 3.2 \\
\hline Std. Deviation & 1.6 & 1.5 & 1.6 & 1.5 & 1.7 & 1.5 & 1.8 & 1.8 & 1.7 \\
\hline Min & 1 & 1 & 1 & 1 & 1 & 1 & 1 & 1 & 1 \\
\hline Max & 11 & 8 & 8 & 8 & 11 & 7 & 10 & 11 & 9 \\
\hline \multicolumn{10}{|l|}{ Employment Status } \\
\hline $\mathrm{N}$ & 1488 & 392 & 145 & 161 & 231 & 147 & 184 & 82 & 142 \\
\hline
\end{tabular}




\begin{tabular}{|c|c|c|c|c|c|c|c|c|c|}
\hline Self-employed & $9 \%$ & $4 \%$ & $5 \%$ & $17 \%$ & $5 \%$ & $8 \%$ & $14 \%$ & $17 \%$ & $14 \%$ \\
\hline Full-time & $37 \%$ & $41 \%$ & $36 \%$ & $34 \%$ & $34 \%$ & $44 \%$ & $34 \%$ & $26 \%$ & $36 \%$ \\
\hline Part-time & $8 \%$ & $7 \%$ & $10 \%$ & $5 \%$ & $8 \%$ & $4 \%$ & $10 \%$ & $5 \%$ & $11 \%$ \\
\hline Student & $6 \%$ & $3 \%$ & $12 \%$ & $3 \%$ & $9 \%$ & $9 \%$ & $4 \%$ & $11 \%$ & $0 \%$ \\
\hline Keep house & $20 \%$ & $27 \%$ & $27 \%$ & $17 \%$ & $20 \%$ & $20 \%$ & $13 \%$ & $21 \%$ & $8 \%$ \\
\hline Others & $18 \%$ & $18 \%$ & $10 \%$ & $24 \%$ & $24 \%$ & $15 \%$ & $25 \%$ & $21 \%$ & $30 \%$ \\
\hline Unemployed & $2 \%$ & $4 \%$ & $1 \%$ & $3 \%$ & $2 \%$ & $2 \%$ & $4 \%$ & $5 \%$ & $1 \%$ \\
\hline \multicolumn{10}{|l|}{ Log of income } \\
\hline $\mathrm{N}$ & 1473 & 388 & 144 & 159 & 225 & 142 & 180 & 80 & 140 \\
\hline Mean & 9.9 & 9.9 & 10.0 & 9.9 & 9.9 & 10.1 & 9.8 & 9.9 & 9.9 \\
\hline Std. Deviation & 0.4 & 0.3 & 0.3 & 0.3 & 0.3 & 0.5 & 0.4 & 0.4 & 0.4 \\
\hline Min & 8.2 & 8.7 & 8.3 & 8.8 & 8.5 & 8.2 & 8.4 & 8.7 & 9.2 \\
\hline Max & 10.5 & 10.5 & 10.5 & 10.5 & 10.5 & 10.5 & 10.5 & 10.5 & 10.5 \\
\hline \multicolumn{10}{|c|}{ Log of house prices } \\
\hline $\mathrm{N}$ & 1276 & 245 & 142 & 146 & 181 & 101 & 151 & 80 & 138 \\
\hline Mean & 12.6 & 12.9 & 12.6 & 12.4 & 12.6 & 12.3 & 12.5 & 12.4 & 12.5 \\
\hline Std Deviation & 0.4 & 0.4 & 0.3 & 0.4 & 0.3 & 0.4 & 0.3 & 0.3 & 0.4 \\
\hline Min & 11.2 & 11.5 & 11.8 & 11.4 & 11.5 & 11.5 & 11.7 & 11.7 & 11.7 \\
\hline Max & 13.8 & 13.8 & 13.7 & 13.4 & 13.5 & 13.1 & 13.3 & 13.2 & 13.7 \\
\hline
\end{tabular}


Table 3. Descriptive statistics of environmental variables

\begin{tabular}{|c|c|c|c|c|c|c|c|c|c|}
\hline & Ireland & Dublin & Mid-East & South East & South West & Mid-West & Border & Midland & West \\
\hline \multicolumn{10}{|c|}{ January mean daily minimum temp $\left({ }^{\circ} \mathrm{C}\right)$} \\
\hline $\mathrm{N}$ & 1480 & 390 & 145 & 160 & 230 & 147 & 183 & 82 & 142 \\
\hline Mean & 2.6 & 2.6 & 1.6 & 2.3 & 2.8 & 2.2 & 2.3 & 1.6 & 2.3 \\
\hline Std. Deviation & 0.6 & 0.4 & 0.4 & 0.6 & 0.6 & 0.2 & 0.7 & 0.2 & 0.5 \\
\hline Min & 1.5 & 2.0 & 1.5 & 1.5 & 2.0 & 2.0 & 1.5 & 1.5 & 1.5 \\
\hline Max & 4.0 & 3.0 & 2.5 & 3.0 & 4.0 & 2.5 & 3.5 & 2.0 & 3.5 \\
\hline \multicolumn{10}{|c|}{ July mean daily maximum temp $\left({ }^{\circ} \mathrm{C}\right)$} \\
\hline $\mathrm{N}$ & 1448 & 390 & 145 & 160 & 230 & 115 & 183 & 82 & 142 \\
\hline Mean & 19.2 & 19.5 & 19.6 & 19.8 & 19.5 & 19.1 & 18.2 & 19.6 & 18.3 \\
\hline Std. Deviation & 0.7 & 0.4 & 0.4 & 0.2 & 0.6 & 0.3 & 0.7 & 0.3 & 0.5 \\
\hline Min & 17 & 18.5 & 19.0 & 19.5 & 18.5 & 18.5 & 17.0 & 19.0 & 17.5 \\
\hline Max & 20 & 20.0 & 20.0 & 20.0 & 20.0 & 19.5 & 19.0 & 20.0 & 19.0 \\
\hline \multicolumn{10}{|c|}{ Annual mean ambient mass concentration of $P M_{10}\left(\mu \mathrm{g} / \mathrm{m}^{3}\right)$} \\
\hline $\mathrm{N}$ & 1500 & 392 & 145 & 161 & 231 & 147 & 184 & 82 & 142 \\
\hline Mean & 20.8 & 24.0 & 19.0 & 19.2 & 21.0 & 19.8 & 19.0 & 19.1 & 19.7 \\
\hline Std. Deviation & 3.7 & 5.3 & 0.0 & 0.9 & 3.2 & 1.9 & 0.0 & 0.6 & 1.7 \\
\hline Min & 19.0 & 19.0 & 19.0 & 19.0 & 19.0 & 19.0 & 19.0 & 19.0 & 19.0 \\
\hline $\operatorname{Max}$ & 38.0 & 38.0 & 19.0 & 24.0 & 26.0 & 24.0 & 19.0 & 24.0 & 24.0 \\
\hline \multicolumn{10}{|c|}{ Mean annual precipitation $(\mathrm{mm})$} \\
\hline $\mathrm{N}$ & 1480 & 390 & 145 & 160 & 230 & 147 & 183 & 82 & 142 \\
\hline Mean & 1000.5 & 834.1 & 1038.6 & 988.8 & 1193 & 1009 & 1078.7 & 909.8 & 1063.4 \\
\hline Std. Deviation & 244 & 74.1 & 399.0 & 79.3 & 355 & 74.3 & 221.2 & 29.9 & 102 \\
\hline Min & 700 & 700 & 800 & 900 & 1000 & 900 & 900 & 900 & 1000 \\
\hline $\operatorname{Max}$ & 2000 & 1000 & 2000 & 1200 & 2000 & 1200 & 1600 & 1000 & 1600 \\
\hline \multicolumn{10}{|c|}{ People living within $5 \mathrm{Km}$ from a seriously polluted river (1/0) } \\
\hline $\mathrm{N}(\%)$ & $31 \%$ & $46 \%$ & $21 \%$ & $0 \%$ & $0 \%$ & $0 \%$ & $10 \%$ & $0 \%$ & $0 \%$ \\
\hline \multicolumn{10}{|c|}{ People living within $5 \mathrm{Km}$ from a landfill in the respondent's ED } \\
\hline $\mathrm{N}(\%)$ & $4 \%$ & $27 \%$ & $10 \%$ & $11 \%$ & $16 \%$ & $10 \%$ & $12 \%$ & $6 \%$ & $9 \%$ \\
\hline \multicolumn{10}{|c|}{ People living within $5 \mathrm{Km}$ from a coast in the respondent's ED } \\
\hline $\mathrm{N}(\%)$ & $50 \%$ & $27 \%$ & $10 \%$ & $11 \%$ & $16 \%$ & $10 \%$ & $12 \%$ & $6 \%$ & $9 \%$ \\
\hline
\end{tabular}


Table 4. Regional dummies in SWB regressions

\begin{tabular}{lll}
\hline & Full sample & \multicolumn{1}{c}{$\begin{array}{l}\text { One-person } \\
\text { households }\end{array}$} \\
\hline Individual Characteristics & Yes & Yes \\
Dublin Region & $-0.456^{* * *}$ & $-0.516^{*}$ \\
& $(0.135)$ & $(0.285)$ \\
Mid-East region & 0.182 & 0.0667 \\
& $(0.266)$ & $(0.366)$ \\
South-West region & 0.0990 & 0.424 \\
& $(0.225)$ & $(0.480)$ \\
South East & 0.262 & 0.586 \\
& $(0.221)$ & $(0.367)$ \\
Mid West & 0.0644 & 0.0724 \\
Border & $(0.135)$ & $(0.305)$ \\
& -0.107 & 0.162 \\
West & $(0.120)$ & $(0.231)$ \\
& $0.827 * * *$ & $1.287 * * *$ \\
N & $(0.261)$ & $(0.436)$ \\
R-squared & 1442 & 166 \\
\hline Note: Standard errors in parenthesis. They were adjusted for clustering within electoral divisions (Moulton, 1990; \\
Williams, 2000). The reference group is the Midland Region. $* * * * *$ and * denote statistical significance at 1\%, 5\% \\
and 10\% levels, respectively. & & 0.38
\end{tabular}


Table 5. SWB regressions, full set of coefficients and monetary values

\begin{tabular}{|c|c|c|c|c|c|c|}
\hline & $\begin{array}{c}(1) \\
\text { Baseline }\end{array}$ & $\begin{array}{c}(2) \\
+ \text { Urban } \\
+ \text { Roads }\end{array}$ & $\begin{array}{c}(3) \\
+ \text { Pop } \\
\text { dens }+ \\
\text { crime }\end{array}$ & $\begin{array}{c}(4) \\
\text { No self- } \\
\text { employed }\end{array}$ & $\begin{array}{c}\text { (5) } \\
\text { One- } \\
\text { person } \\
\text { households }\end{array}$ & $\begin{array}{l}\text { (6) } \\
\text { IV }\end{array}$ \\
\hline \multirow[t]{2}{*}{$\overline{\text { Age }}$} & 0.005 & 0.005 & 0.004 & 0.005 & $0.014^{*}$ & 0.003 \\
\hline & $(0.003)$ & $(0.003)$ & $(0.003)$ & $(0.004)$ & $(0.008)$ & $(0.003)$ \\
\hline \multirow[t]{2}{*}{ Female } & 0.043 & 0.046 & 0.041 & 0.059 & -0.100 & -0.001 \\
\hline & $(0.075)$ & $(0.074)$ & $(0.074)$ & $(0.078)$ & $(0.174)$ & $(0.071)$ \\
\hline \multirow[t]{2}{*}{ Family size (\#components) } & -0.017 & -0.020 & -0.017 & -0.017 & - & -0.029 \\
\hline & $(0.022)$ & $(0.022)$ & $(0.022)$ & $(0.024)$ & - & $(0.030)$ \\
\hline \multirow[t]{2}{*}{ Married } & $-0.230 * *$ & $-0.235 * *$ & $-0.225 *$ & $-0.243 * *$ & $-0.766^{* *}$ & -0.049 \\
\hline & $(0.112)$ & $(0.113)$ & $(0.114)$ & $(0.120)$ & $(0.370)$ & $(0.095)$ \\
\hline \multirow[t]{2}{*}{ Cohabit } & -0.267 & $-0.276^{*}$ & -0.243 & $-0.300 *$ & - & -0.019 \\
\hline & $(0.162)$ & $(0.158)$ & $(0.153)$ & $(0.173)$ & - & $(0.142)$ \\
\hline \multirow[t]{2}{*}{ Primary School } & 0.155 & 0.132 & 0.125 & 0.238 & 0.586 & -0.014 \\
\hline & $(0.189)$ & $(0.192)$ & $(0.194)$ & $(0.188)$ & $(0.465)$ & $(0.148)$ \\
\hline \multirow[t]{2}{*}{ Lower Secondary School } & 0.227 & $0.233^{*}$ & $0.234^{*}$ & $0.256^{*}$ & 0.293 & 0.068 \\
\hline & $(0.137)$ & $(0.137)$ & $(0.138)$ & $(0.135)$ & $(0.362)$ & $(0.122)$ \\
\hline \multirow[t]{2}{*}{ Upper Secondary School } & 0.129 & 0.126 & 0.129 & $0.153^{*}$ & 0.339 & 0.099 \\
\hline & $(0.085)$ & $(0.084)$ & $(0.084)$ & $(0.090)$ & $(0.288)$ & $(0.080)$ \\
\hline \multirow[t]{2}{*}{ Self-employed } & 0.143 & 0.156 & 0.161 & - & -0.054 & -0.102 \\
\hline & $(0.112)$ & $(0.113)$ & $(0.112)$ & - & $(0.324)$ & $(0.179)$ \\
\hline \multirow[t]{2}{*}{ Part-time } & -0.112 & -0.118 & -0.113 & -0.142 & -0.778 & -0.182 \\
\hline & $(0.169)$ & $(0.161)$ & $(0.161)$ & $(0.166)$ & $(0.543)$ & $(0.180)$ \\
\hline \multirow[t]{2}{*}{ Full-time } & 0.001 & 0.000 & 0.011 & -0.019 & 0.142 & -0.016 \\
\hline & $(0.118)$ & $(0.119)$ & $(0.118)$ & $(0.119)$ & $(0.421)$ & $(0.153)$ \\
\hline \multirow[t]{2}{*}{ Student } & 0.179 & 0.205 & 0.199 & 0.156 & - & 0.156 \\
\hline & $(0.193)$ & $(0.193)$ & $(0.191)$ & $(0.190)$ & - & $(0.296)$ \\
\hline \multirow[t]{2}{*}{ Keeping House } & -0.007 & -0.010 & 0.003 & -0.024 & 0.194 & -0.211 \\
\hline & $(0.131)$ & $(0.134)$ & $(0.132)$ & $(0.128)$ & $(0.234)$ & $(0.165)$ \\
\hline \multirow[t]{2}{*}{ Unemployed } & $-0.711 * * *$ & $-0.710 * * *$ & $-0.698 * * *$ & $-0.715^{* * *}$ & -0.459 & $-0.780 * *$ \\
\hline & $(0.224)$ & $(0.226)$ & $(0.224)$ & $(0.226)$ & $(0.479)$ & $(0.313)$ \\
\hline \multirow[t]{2}{*}{ Dublin Region } & $-0.624 * *$ & -0.462 & -0.378 & $-0.632 * *$ & -0.570 & $-0.468 *$ \\
\hline & $(0.277)$ & $(0.287)$ & $(0.286)$ & $(0.283)$ & $(0.514)$ & $(0.256)$ \\
\hline Mid East Region & 0.199 & 0.185 & 0.186 & 0.227 & 0.026 & 0.022 \\
\hline
\end{tabular}




\begin{tabular}{|c|c|c|c|c|c|c|}
\hline & $(0.259)$ & $(0.251)$ & $(0.251)$ & $(0.248)$ & $(0.393)$ & $(0.217)$ \\
\hline \multirow[t]{2}{*}{ South West Region } & -0.284 & -0.216 & -0.229 & -0.314 & 0.134 & 0.019 \\
\hline & $(0.254)$ & $(0.236)$ & $(0.233)$ & $(0.258)$ & $(0.563)$ & $(0.205)$ \\
\hline \multirow[t]{2}{*}{ South East Region } & -0.101 & -0.109 & -0.083 & -0.149 & 0.119 & 0.157 \\
\hline & $(0.222)$ & $(0.217)$ & $(0.219)$ & $(0.246)$ & $(0.409)$ & $(0.217)$ \\
\hline \multirow[t]{2}{*}{ Mid West Region } & 0.047 & 0.183 & 0.186 & -0.004 & 0.059 & 0.052 \\
\hline & $(0.167)$ & $(0.217)$ & $(0.212)$ & $(0.170)$ & $(0.383)$ & $(0.170)$ \\
\hline \multirow[t]{2}{*}{ Border Region } & -0.126 & -0.027 & -0.061 & -0.141 & 0.216 & -0.292 \\
\hline & $(0.167)$ & $(0.212)$ & $(0.212)$ & $(0.161)$ & $(0.350)$ & $(0.191)$ \\
\hline \multirow[t]{2}{*}{ West Region } & $0.785 * * *$ & $0.873 * * *$ & $0.829 * * *$ & $0.797 * * *$ & $1.167 * *$ & $0.544 * *$ \\
\hline & $(0.261)$ & $(0.301)$ & $(0.303)$ & $(0.247)$ & $(0.493)$ & $(0.246)$ \\
\hline \multirow{2}{*}{$\begin{array}{l}\text { Proximity severely polluted } \\
\quad \text { river }(5 \mathrm{Km})\end{array}$} & -0.208 & -0.170 & -0.155 & -0.226 & -0.319 & -0.040 \\
\hline & $(0.192)$ & $(0.183)$ & $(0.184)$ & $(0.194)$ & $(0.219)$ & $(0.155)$ \\
\hline \multirow[t]{2}{*}{ Proximity landfill (5Km) } & -0.025 & -0.061 & -0.134 & -0.019 & 0.259 & -0.087 \\
\hline & $(0.203)$ & $(0.189)$ & $(0.184)$ & $(0.203)$ & $(0.433)$ & $(0.167)$ \\
\hline \multirow[t]{2}{*}{ Proximity coast $(5 \mathrm{Km})$} & -0.146 & -0.047 & -0.027 & -0.139 & -0.106 & $-0.231 *$ \\
\hline & $(0.144)$ & $(0.172)$ & $(0.171)$ & $(0.150)$ & $(0.226)$ & $(0.139)$ \\
\hline \multirow{2}{*}{$\begin{array}{l}\text { Mean annual precipitation } \\
(\mathrm{mm})\end{array}$} & -0.000 & -0.000 & -0.000 & -0.000 & -0.001 & -0.000 \\
\hline & $(0.000)$ & $(0.000)$ & $(0.000)$ & $(0.000)$ & $(0.001)$ & $(0.000)$ \\
\hline \multirow{2}{*}{$\begin{array}{l}\text { January mean daily min } \\
\text { temperature }\end{array}$} & $0.547 * * *$ & $0.519 * * *$ & $0.495 * *$ & $0.552 * * *$ & $0.679 * *$ & $0.457 * * *$ \\
\hline & $(0.175)$ & $(0.184)$ & $(0.188)$ & $(0.178)$ & $(0.319)$ & $(0.174)$ \\
\hline \multirow{2}{*}{$\begin{array}{l}\text { July mean daily max } \\
\text { temperature }\end{array}$} & $0.202 *$ & $0.279 *$ & $0.252 *$ & $0.208 *$ & 0.261 & -0.040 \\
\hline & $(0.119)$ & $(0.142)$ & $(0.141)$ & $(0.118)$ & $(0.192)$ & $(0.121)$ \\
\hline \multirow{2}{*}{$\begin{array}{l}\text { Annual mean concentration } \\
\text { of } \mathrm{PM}_{10}\left(\text { micrograms } / \mathrm{m}^{3}\right)\end{array}$} & $-0.033 *$ & -0.021 & -0.011 & $-0.035^{*}$ & $-0.097 * *$ & $-0.043 * *$ \\
\hline & $(0.020)$ & $(0.018)$ & $(0.017)$ & $(0.021)$ & $(0.041)$ & $(0.019)$ \\
\hline \multirow{2}{*}{$\begin{array}{l}\text { Proximity to urban centre } \\
(5 \mathrm{Km})\end{array}$} & - & -0.272 & -0.276 & - & - & - \\
\hline & - & $(0.170)$ & $(0.166)$ & - & - & - \\
\hline \multirow{2}{*}{$\begin{array}{l}\text { Proximity to major road } \\
(5 \mathrm{Km})\end{array}$} & - & -0.049 & -0.041 & - & - & - \\
\hline & - & $(0.146)$ & $(0.143)$ & - & - & - \\
\hline \multirow{2}{*}{$\begin{array}{l}\text { Population density at ED } \\
\text { level }\end{array}$} & - & - & 0.000 & - & - & - \\
\hline & - & - & $(0.003)$ & - & - & - \\
\hline \multirow[t]{2}{*}{ Crime rate at LA level } & - & - & $-0.004 *$ & - & - & - \\
\hline & - & - & $(0.002)$ & - & - & - \\
\hline \multirow[t]{2}{*}{ Log of house prices } & -0.005 & -0.006 & 0.009 & -0.036 & -0.257 & -0.070 \\
\hline & $(0.084)$ & $(0.083)$ & $(0.085)$ & $(0.087)$ & $(0.244)$ & $(0.086)$ \\
\hline Log of income & $0.807 * * *$ & $0.794 * * *$ & $0.753 * * *$ & $0.892 * * *$ & $1.242 * *$ & - \\
\hline
\end{tabular}




$\begin{array}{lcccccc} & (0.261) & (0.262) & (0.268) & (0.266) & (0.505) & - \\ \text { Instrumental income variable } & - & - & - & - & - & 0.523^{* * *} \\ & - & - & - & - & - & (0.177) \\ \text { Constant } & -6.624^{*} & -8.186^{* *} & -7.517^{*} & -7.161^{* *} & -8.209 & 2.409 \\ & (3.477) & (3.935) & (3.967) & (3.523) & (7.397) & (2.741) \\ \text { Observations } & 1184 & 1184 & 1182 & 1071 & 162 & 777 \\ \text { R-squared } & 0.229 & 0.237 & 0.242 & 0.233 & 0.433 & 0.285\end{array}$

\section{Monetary values}

\begin{tabular}{|c|c|c|c|c|c|c|}
\hline MRS January $\left(€ /{ }^{\circ} \mathrm{C}\right.$ year $)$ & $15585^{* *}$ & 15046 & 15121 & $14181 * *$ & 7366 & $20104 *$ \\
\hline MRS July (€/ ${ }^{\circ} \mathrm{C}$ year) & 5759 & 8082 & 7683 & 5326 & 2835 & -1771 \\
\hline MRS $\operatorname{PM}_{10}\left(€ / \mu \mathrm{g} / \mathrm{m}^{3}\right.$ year $)$ & -945 & -615 & -328 & -905 & -1056 & $-1907 *$ \\
\hline $\mathrm{CS}$ January $\left(€ /{ }^{\circ} \mathrm{C}\right.$ year $)$ & $4230 * *$ & $4098 * *$ & $4117 * *$ & $3883 * *$ & $2038 *$ & $5305 * *$ \\
\hline CS July $\left(€ /{ }^{\circ} \mathrm{C}\right.$ year) & 1664 & $2301 *$ & $2193 *$ & 1543 & 824 & -537 \\
\hline $\mathrm{CS} \mathrm{PM}_{10}\left(€ / \mu \mathrm{g} / \mathrm{m}^{3}\right.$ year $)$ & -3231 & -2055 & -1075 & -3086 & -3839 & $-6990 *$ \\
\hline ES January $\left(€ /{ }^{\circ} \mathrm{C}\right.$ year $)$ & $5185^{*}$ & $4988 *$ & $5015^{*}$ & $4675^{*}$ & 2401 & $6895^{*}$ \\
\hline :ES July $\left(€ /{ }^{\circ} \mathrm{C}\right.$ year $)$ & 1794 & 2557 & 2424 & 1655 & 878 & -525 \\
\hline $\mathrm{ES} \mathrm{PM}_{10}\left(€ / \mu \mathrm{g} / \mathrm{m}^{3}\right.$ year $)$ & -2832 & -1887 & -1027 & -2719 & $-2988 *$ & $-5362 * *$ \\
\hline
\end{tabular}

Note: Standard errors in parenthesis. They were adjusted for clustering within EDs (Moulton, 1990; Williams, 2000). $* * *, * * *$ denote statistical significance at 1,5 and $10 \%$ levels, respectively. The bottom nine rows of the Table report the monetary values calculated as specified in Section 3.2. MRS January (MRS July) stands for the Marginal Rate of Substitution (MRS) between income and an increase in minimum daily mean temperature in January (maximum daily mean temperature in July) by one degree centigrade. MRS $\mathrm{PM}_{10}$ shows the MRS between income and an increase in the mean annual concentration of $\mathrm{PM}_{10}$ of one microgram per cubic meter. CS January shows the WTP (compensating surplus) for an increase in January temperature from 2.3 degrees centigrade (the average temperature in Ireland) to 2.6 degrees centigrade (the average temperature in the Dublin Region, the capital's region). CS July shows the WTP for an increase of temperature from the average July temperature in Ireland (19.2 degrees centigrade) to the temperature experienced in Dublin (19.5 degrees centigrade). CS PM 10 shows the willingness to accept (see the negative signs) of an average Irish individual in order to avoid an increase of $\mathrm{PM}_{10}$ concentration equal to the one in Dublin. ES expresses the same changes in terms of the minimum amount of income that the same individual would need in order to attain the higher level of utility he would have reached if the changes were not to occur 